\title{
A versatile cat-restraint system
}

\author{
ANTHONY G. ROMANO, JOSEPH E. STEINMETZ, and MICHAEL M. PATTERSON \\ Ohio University, Athens, Ohio 45701
}

\begin{abstract}
A new method and apparatus for restraining the awake cat is described. The restraint system comfortably and adequately restrains virtually any cat and requires little or no adaptation. The restraint box is inexpensive to construct, lightweight, and portable. The unit requires minimal maintenance, can be easily used by one person, and may be modified for use in a variety of situations.
\end{abstract}

The cat has long been a favorite subject for studies of basic neural processes in both the brain and spinal cord and has one of the best understood of all mammalian nervous systems. Given the availability of this information, it would be desirable to undertake neurophysiological analyses of simple learning processes in the cat. However, the cat's inherent dislike of restraint has precluded the development of an easily used behavioral paradigm such as that developed by Gormezano and his colleagues (Gormezano, Schneiderman, Deaux, \& Fuentes, 1962) for the rabbit and subsequently used in studies concerned with brain-behavior correlations (e.g., Berger, Alger, \& Thompson, 1976).

Several methods have been devised for restraining the awake cat, including simply paralyzing the animal and measuring either autonomic response parameters (e.g., Weinberger, Oleson, \& Haste, 1973) or neural responses at the periphery (e.g., Woody \& Brozek, 1969a, 1969b). This approach, while simplifying restraint problems, negates correlation of overt skeletal behaviors with brain activity and does not allow determination of the conversion of neural to peripheral skeletal behaviors. Wickens and his colleagues have utilized a sling (Wickens, Meyer, \& Sullivan, 1961). While such devices have been successfully used in behavioral and physiological studies (e.g., Adams, 1963; Bruner, 1969; Conner, Rossi, \& Baker, 1966), sling restraint systems generally require extensive periods of adaptation before stimuli can be presented without undue struggling. A similar restraint apparatus, described by Hall and Monto (1970), allows free head movement but requires some adaptation and two people to use it. O'Brien and Packham (1973) describe a restraint method consisting of a system of casts placed over the animal. This allows full-body restraint and recording of leg movements, but it results in a rather low level of conditioned responding (22\%). Other investigators have used invasive restraint methods, such as placing the animal in a box and fastening bolts implanted in the skull to a metal band (Hobson, 1972) or using

The development of the apparatus and techniques presented in this report was supported in part by NINCDS Grants NS 14545 and NS1067. Requests for reprints should be addressed to Michael M. Patterson, College of Osteopathic Medicine, Ohio University, Athens, Ohio 45701 . a body box with a head holder fastened to an acrylic pedestal affixed to the skull (Wolfe, 1969). When many subjects are to be used, such procedures, while holding the animal's head firmly, are inefficient due to the time involved in the implantation procedures.

We have developed a versatile system of cat restraint that is used primarily for conditioning the nictitating membrane (NM) response (Patterson, Olah, \& Clement, 1977). The major advantage of this system is that it requires little or no adaptation and is tolerated well by the animal.

\section{SYSTEM DESCRIPTION}

The basic equipment, schematized in Figure 1, consists of a thick-walled Plexiglas restraint box similar to, but more enclosed than, the rabbit box described by Gormezano (1966). The bottom of the box measures $45.1 \mathrm{~cm}$ long $\times 15.2 \mathrm{~cm}$ wide. The hinged lid measures $31.4 \mathrm{~cm}$ long, and the height of the box is $15.6 \mathrm{~cm}$. Viewed from behind, the inside of the box is octagonal up to the front edge of the hinged lid, with each side of the octagon measuring $5.2 \mathrm{~cm}$. An adjustable end plate is used to accommodate cats of various sizes and can be locked in place in any one of six positions in the rear $9 \mathrm{~cm}$ of the box. The front end of the box consists of an adjustable neck yoke and a chin plate to which two nylon releasable cable ties and a bite bar (labeled $\mathrm{C}$ in Figure 1) are attached. The neck yoke measures $12.7 \times 8.9 \mathrm{~cm}$; the chin plate is $8.6 \mathrm{~cm}$ wide and protrudes $9.2 \mathrm{~cm}$ beyond the bottom of the front of the box. The animal's chin rests in a 5-mm-deep trough cut into the chin plate. The trough measures $4.1 \mathrm{~cm}$ at its widest point and tapers to $1 \mathrm{~cm}$ at its front edge.

The cat is placed in the restraint box lying on its stomach with its forelegs slightly extended and its hindlegs tucked underneath the body in a manner similar to that of the rabbit in a Gormezano (1966) box. The lid of the box is closed and fastened, and the end plate is locked into the desired position. If further body restraint is required for smaller cats, paint rollers may be inserted between the animal's body and the lid of the box. The cat's head protrudes through the neck yoke, with its chin resting in the trough. The two cable ties, which fit 

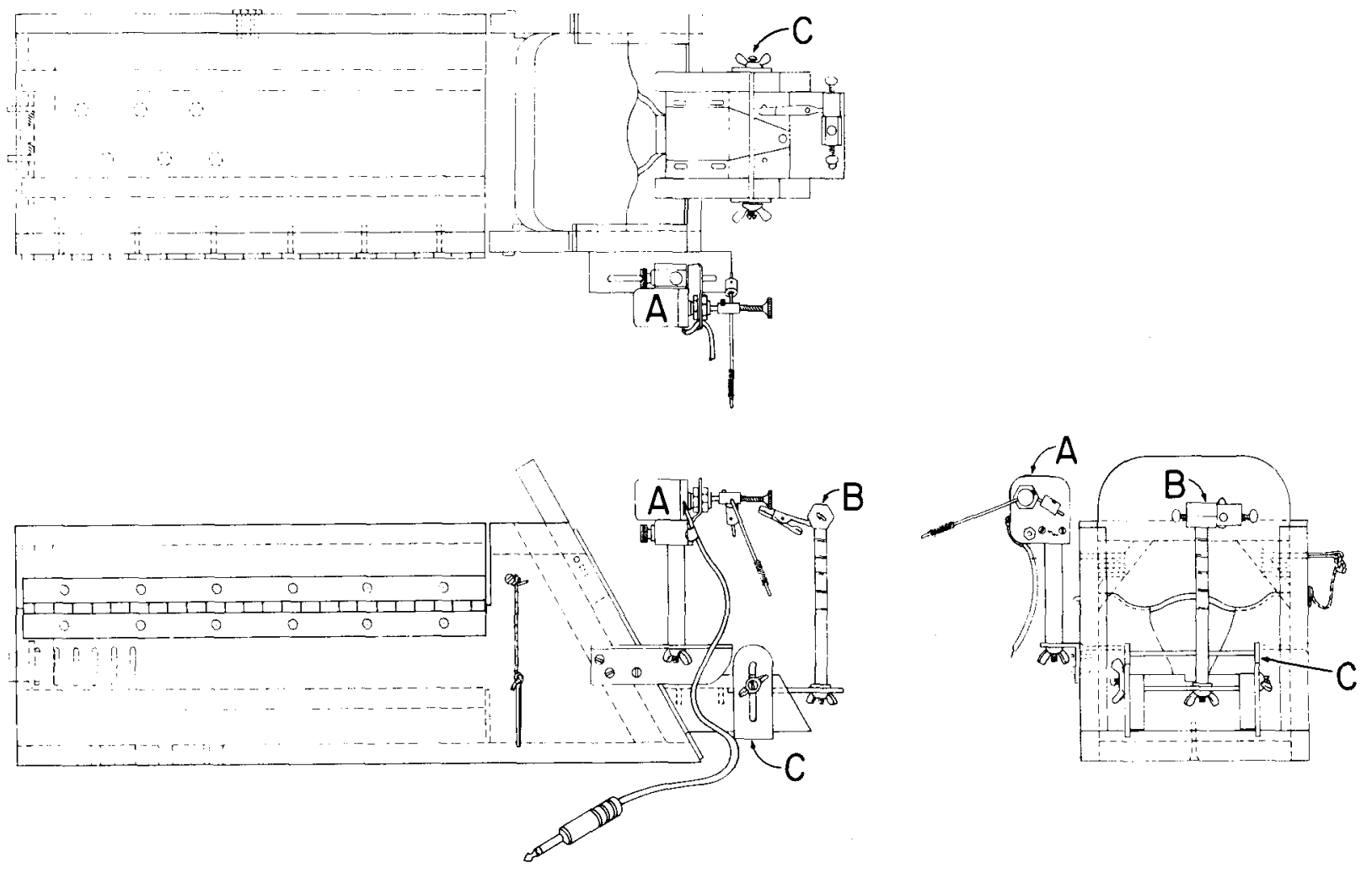

Figure 1. Schematic view of cat restraint box with (A) rotary potentiometer, (B) shock lead holder, and (C) bite bar.

through slots in the chin plate, are tightened around the head, in front of and behind the ears. The cable ties are positioned so as to allow easy access to electrode implants or cannulas over most of the surface of the skull. The bite bar is positioned behind the lower canines and is tightened sufficiently to preclude head rotation without producing discomfort. As indicated earlier, the present restraining system alleviates the problem of lengthy adaptation sessions; the cats accept this restraint for as long as $2 \mathrm{~h}$ with little struggling after a single adaptation session of $1 \mathrm{~h}$. No appreciable increase in resistance to being placed in the apparatus has developed over 15 days in our studies. Furthermore, the restraint sytem is simple enough to be easily used by one person.

The versatility of the restraint system is one of its greatest advantages. A cat can be held sufficiently secure to permit NM or eyelid conditioning. For NM conditioning, a metal plate overlapping and protruding $4.7 \mathrm{~cm}$ beyond the front edge of the chin rest supports an upright shaft and sliding collar to which an alligator clip is attached (labeled B in Figure 1). The alligator clip holds the shock leads that deliver the UCS to the eye region. The sliding collar may be locked in place at any point along the shaft, and a slot in the metal plate allows the shaft to be moved laterally. A similar assembly is employed to position a rotary potentiometer (labeled A in Figure 1) that is used to monitor NM movements. A

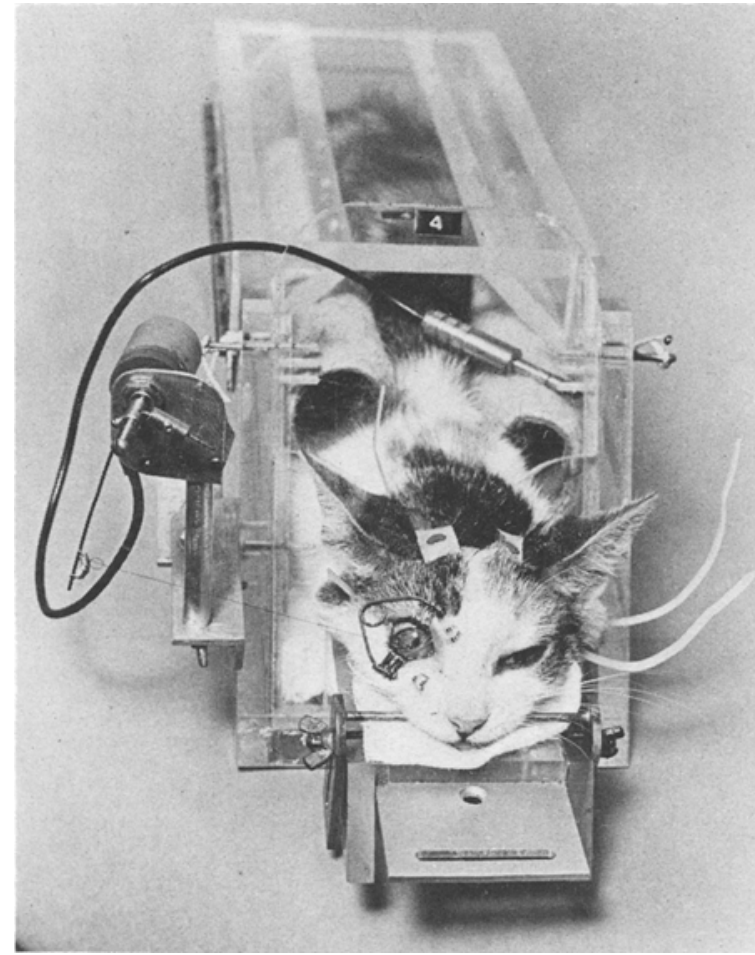

Figure 2. Cat prepared for nictitating membrane conditioning. 
slotted metal bracket mounted on the front of one side of the box supports a shaft and the sliding collar to which the potentiometer is attached. Thus, the potentiometer may be adjusted to any position necessary for optimal monitoring of NM movements. The potentiometer arm is connected to the NM via a thread and hook that hook into a small nylon loop sutured into the NM. Figure 2 shows a cat prepared for NM conditioning. Polygraph tracings from two cats undergoing NM conditioning are depicted in Figure 3. The first vertical line is CS onset, and the second is UCS onset. The upper subject shows only the unconditioned response (UCR) to shock; the lower subject shows both conditioned and unconditioned responses. Note the response definition and the lack of spontaneous movements during the trial period. For further details regarding cat NM conditioning, see Patterson et al. (1977). The same restraint system was employed by Patterson, Berger, and

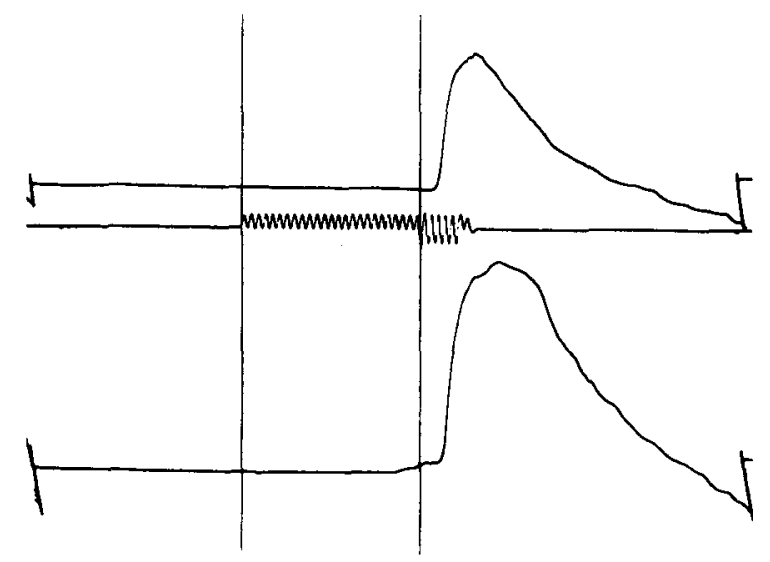

Figure 3. Polygraph record of two typical cat nictitating membrane responses. See text for details.

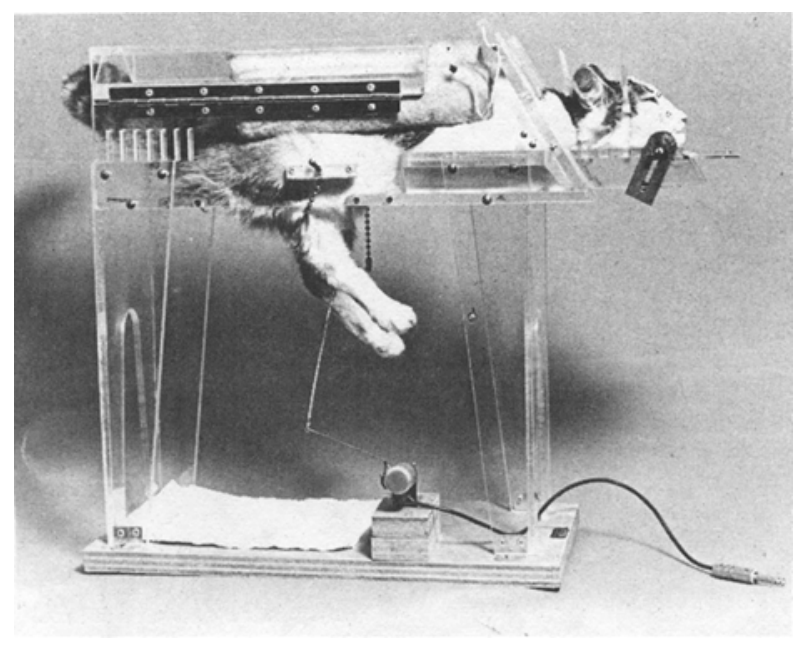

Figure 4. Cat prepared for hindleg flexion conditioning in modified restraint box.

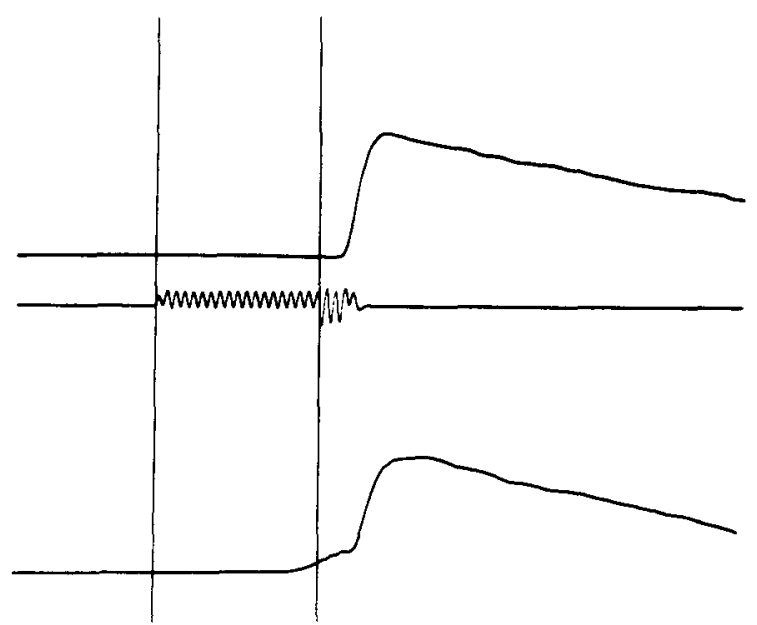

Figure 5. Polygraph record of two typical cat hindleg flexion responses. See text for details.

Thompson (1979) in a study correlating NM conditioning with hippocampal multiple-unit activity. Use of the restrainer resulted in excellent behavioral response measurements, as well as an artifact-free stable hippocampal record.

We have modified the restraint box to permit hindleg flexion conditioning. The modifications make the hindleg accessible by opening holes in the bottom of the box, raising the box on four Plexiglas legs attached to a wooden base, and mounting a potentiometer on the base to monitor leg movements. Figure 4 shows a cat in a modified box. Polygraph tracings from two cats undergoing leg flexion conditioning are shown in Figure 5. The first and second vertical lines represent CS and UCS onset, respectively. Thus, the upper subject shows only the unconditioned response to shock; the lower subject exhibits a conditioned response in addition to the unconditioned response. Note, again, the response definition and lack of spontaneous movements during the trial period.

\section{REFERENCES}

Adams, $T$. Hypothalamic temperature in the cat during feeding and sleeping. Science, 1963, 139, 609-610.

Beritir, T. W., Algik, B., \& Thompson, R. F. Neuronal substrate of classical conditioning in the hippocampus. Science, $1976,192,483-485$.

Bruner, A. Reinforcement strength during classical conditioning of leg flexion, freezing, and heart rate in cats. Conditional Reflex, 1969. 4, 24-31.

Connti, J., Rossi, G., \& Baker, W. Characteristics of tremor in cats following injections of carbachol into the caudate nucleus. Experimental Neurslogy, 1966, 14, 371-382.

Gormbzano, I. Classical conditioning. In J. B. Sidowski (Ed.), Experimental methods and instrumentation in psvchology. New York: McGraw-Hill, 1966.

Gormezano, I., Scinifibirman, N., Draux, E., \& Fuentes, I. Nictitating membrane: Classical conditioning and extinction in the albino rabbit. Science, 1962, 138, 33-34. 
Hall, R. A., \& Monto, A. V. A cat restraining device for the awake animal. Psychophysiology, 1970, 6, 609-610.

Hobson, J. A. A method of head restraint for cats. Electroencephalography and Clinical Neurophysiology, 1972, 32, 443-444.

O'Brien, J., \& Packham, S. Conditioned leg movement in the cat with massed trials, trace conditioning, and weak US intensity. Conditional Reflex, 1973, 8, 116-124.

Patterson, M. M., Berger, T. W., \& Thompson, R. F. Neural plasticity recorded from cat hippocampus during classical conditioning. Brain Research, 1979, 163, 339-343.

Patterson, M. M., Olah, J., \& Clement, J. Classical nictitating membrane conditioning in the awake, normal, restrained cat. Science, 1977, 196, 1124-1126.

Weinberger, N., Oleson, T., \& Haste, D. Inhibitory control of the conditional pupillary dilation response in the paralyzed cat. Behavioral Biology, 1973, 9, 307-316.
Wickens, D., Mever, P., \& Sullivan, S. Classical GSR conditioning, conditioned discrimination, and interstimulus intervals in cats. Journal of Comparative and Physiological Psvchology, 1961, 54, 572-576.

WolfE, J. A restraining device for electrophysiological recording in the unanesthetized cat. Physiology \& Behavior, 1969, 4, 119-120.

Woody, C., \& Broze K, G. Changes in evoked responses from facial nucleus of cat with conditioning and extinction of an eye blink. Journal of Neurophysiology, 1969, 32, 717-726. (a)

Woody, C., \& Brozek, G. Gross potential from facial nucleus of the cat as an index of neural activity in response to glabella tap. Journal of Neurophysiology, 1969, 32, 704-716. (b)

(Received for publication July 31, 1980; accepted August 2, 1980.) 